\title{
“TIO, EU GOSTO É DE TRETA!" BRINCANDO E BRIGANDO NA ESCOLA
}

\author{
"HEY TEACHER, I LIKE A SCRAP!" PLAYING AND FIGHTING AT SCHOOL \\ "¡TÍO, LO QUE ME GUSTA ES EL LÍO!" JUGANDO Y PELEANDO EN LA \\ ESCUELA
}

\author{
Mayrhon José Abrantes Farias*, Ingrid Dittrich Wiggers*
}

Palavras chave:

Criança.

Jogos e brinquedos.

Violência.

Conflito.

Keywords:

Child.

Play and playthings.

Violence.

Conflict.

Resumo: $O$ objetivo desta pesquisa é compreender as brincadeiras de lutinha e as brigas vivenciadas no ambiente escolar, sob a perspectiva do cotidiano infantil, em um Centro de Atenção Integral à Criança e ao Adolescente, situado em Sobradinho II - DF. O estudo tem natureza qualitativa, de orientação etnográfica, com os aportes teórico-metodológicos das sociologias do cotidiano e da infância. $O$ trabalho de campo foi realizado ao longo de sete meses do ano letivo de 2017, com trinta e quatro crianças, entre nove e 12 anos de idade. Os instrumentos utilizados foram observação participante, produção de desenhos e conversas com as crianças. Os registros de campo permitiram a identificação de categorias que evidenciam as brincadeiras de lutinha e as brigas sob dimensões paradoxais do cotidiano infantil, que carregam no seu bojo aspectos circundantes ao conflito enquanto mediador das relações concebidas dentro e fora da escola.

Abstract: This study looks into children's play-fighting and real fights experienced in the school environment from the perspective of children's daily life in a Center for Whole Attention to Children and Adolescents located in Sobradinho II, DF, Brazil. It is a qualitative, ethnographic study with theoretical-methodological contributions from Sociologies of Daily Life and Childhood. Field research was conducted over seven months of the 2017 school year, with 34 children aged 9-12. The instruments used were participant observation, drawing, and conversations with the children. Field records allowed identifying categories that show play-fighting and real fights under the paradoxical dimensions of children's daily life, which carry aspects surrounding conflict as a mediator of relationships conceived inside and outside the school.

Palabras clave: Niño.

Juegos y juguetes. Violencia. Conflicto.
Resumen: El objetivo de esta investigación es comprender los juegos de lucha y las peleas vivenciadas en el ambiente escolar, bajo la perspectiva del cotidiano infantil, en un Centro de Atención Integral a Niños y Adolescentes, situado en Sobradinho II - DF. El estudio tiene naturaleza cualitativa, con orientación etnográfica y con los aportes teóricometodológicos de las sociologías de lo cotidiano y de la infancia. La investigación de campo fue realizada a lo largo de siete meses del año 2017, con treinta y cuatro niños de entre 9 y 12 años de edad. Los instrumentos utilizados fueron la observación participante, la producción de dibujos y las conversaciones con los niños. Los registros de campo permitieron la identificación de categorías que evidencian los juegos de lucha y las peleas bajo dimensiones paradójicas del cotidiano infantil, que cargan aspectos circundantes al conflicto como mediador de las relaciones concebidas dentro y fuera de la escuela.
*Universidade de Brasília. Brasília, DF, Brasil.

E-mail: mayrhonfarias@ @otmail.com; ingridwiggers@gmail.com

Recebido em: 22-11-2018 Aprovado em: 10-05-2019 Publicado em: 25-06-2019

DOI: hittps://doi.org/10.22456/1982-8918.88343 (c) (1) (8) Licence 


\section{INTRODUÇÃOO}

As crianças dispõem de diversas formas de brincar e incorporam aspectos da vida cotidiana ao universo lúdico. Dentre os elementos que são tematizados nas brincadeiras, a violência é um ponto que proporciona interpretações dúbias em torno dos limites entre o brincar e o brigar (FARIAS; WIGGERS, 2015). Alguns estudos sugerem que brincadeiras de caráter lúdico-agressivo são prejudiciais às crianças e acreditam, ainda, que elas incitam condutas violentas (CANDREVA et al., 2009). Outros, por sua vez, entendem que essas práticas constituem 0 acervo das produções culturais infantis, ilustrando parte de suas visões de mundo (BARBOSA et al., 2017; FARIAS, 2015).

Para problematizar o que denominou de "brincadeiras violentas" na escola, Rodrigues (2012) utilizou a metáfora "homo ludo-violens", baseada nos conceitos de "homo ludens", cunhado por Huizinga (2010), que reconhece a ludicidade como parte constituidora da própria cultura; bem como de "homo violens", de Dadoun (1998), relacionado ao lado hostil e violento da humanidade. Recorreu, ainda, à compreensão de "brincadeiras ascéticas", problematizadas por Château (1987), que traduz as brincadeiras violentas como práticas que aglutinam sofrimento aos participantes, nas quais o público atua como um importante mediador do "espetáculo".

No bojo dessa discussão situa-se o binômio lúdico/violência, que dispõe de limiaridades ou zonas de rupturas, forjadas nos cotidianos das crianças. Mas quais seriam os limites entre 0 brincar e o brigar? Quais os elementos que formatam essas práticas no cotidiano das crianças? E qual o lugar do corpo na produção dos significados do conflito como categoria que atravessa as narrativas infantis?

Para subsidiar a análise desse fenômeno, consideramos pertinente a noção de conflito referenciada no campo da sociologia. Max Weber (1999), no segundo volume de sua obra clássica Economia e sociedade, sugere o mesmo como uma ação cotidiana e histórica, influenciada, substancialmente, por complexos de dominação. Mediante 0 estudo da ação social, o autor delineia os conflitos como formas de interação entre os atores, dotadas de intencionalidade.

Adicionalmente, Georg Simmel (1983) desenvolveu estudos balizados por uma microssociologia, destacando os conflitos como encontros sociais importantes, pois são formas predominantes nas interações entre pares. Simmel aponta, ainda, para o desenvolvimento da tomada de consciência individual como um dos pontos positivos do conflito, que, segundo ele, corresponde a um processo de negação da unidade.

Sendo assim, o conflito seria uma matriz formal de tensões que intervém no socialmente estabelecido, criando novas formas de sociação. Tal como Simmel, Norbert Elias (2005) considera que as pessoas estão sempre em conflito, sobretudo por poder, muitas vezes, de forma inconsciente. 0 autor sinaliza a disputa por poder como "[...] característica estrutural das relações humanas" (ELIAS, 2005, p. 81).

Nesse contexto, 0 corpo se mostra proeminente não apenas por ser tradutor das relações sociais, mas, sobretudo, por sediar o cruzamento das diversas instâncias da cultura, abarcando, inclusive, a cultura escolar e as culturas infantis. Ademais, as práticas de "luta" de brincadeira, as brincadeiras que encenam brigas imaginárias ou até mesmo as brigas "de verdade" expõem roteiros do cotidiano, evidenciando que o conflito é forjado no próprio corpo, a partir do jogo tenso entre as narrativas dos adultos e das crianças. 
Além do exposto, o presente trabalho levou em conta, de modo específico, referências teórico-metodológicas da sociologia do cotidiano (PAIS, 1993, 2003, 2003a) e de estudos das diferentes matrizes da sociologia da infância (BROUGÈRE, 1998, 2010; CORSARO, 1992, 2005; SARAMAGO, 1994; SIROTA, 2012), que contribuíram para o delineamento do trabalho de campo, bem como análise dos dados produzidos. Em vista disso, o artigo tem como objetivo compreender as brincadeiras de lutinha e as brigas vivenciadas no ambiente escolar, sob a perspectiva do cotidiano infantil. Tivemos como principal escopo, a partir da escolha do referido tema, analisar narrativas das crianças no que tange às zonas de ruptura e continuidade, que transversalizam o imaginário das práticas corporais suscitadas.

\section{DELINEAMENTOS METODOLÓGICOS}

O trabalho de campo foi desenvolvido ao longo de sete meses, em um Centro de Atenção Integral à Criança e ao Adolescente (CAIC) situado em Sobradinho II, região administrativa do Distrito Federal. A escolha do respectivo CAIC como campo de investigação se deu pelo fato de já termos tido uma experiência prévia com a escola, ministrando aulas de Educação Física. Sobretudo, o amplo espaço que a escola oferece, além de equipamentos recreativos e esportivos, atendendo a centenas de alunos de Sobradinho e entorno, da Educação Infantil até o 5a ano, nos apresentou um repertório variado de possibilidades de leitura das infâncias, bem como das brincadeiras de lutinha e das brigas enquanto práticas corporais infantis reproduzidas e ressignificadas no ambiente escolar.

O estudo tem natureza qualitativa, com orientação etnográfica (CORSARO, 2005; GRAUE; WALSH, 2003), pensando as crianças em experiências específicas, nos seus respectivos cotidianos. Além disso, foram utilizadas como técnicas de pesquisa a observação participante a produção de desenhos e as conversas, que compuseram informações registradas em diário de campo, no qual foram expostas as narrativas infantis, para além dos seus gestos, desenhos e falas. Vale ressaltar que algumas das cenas observadas no campo foram organizadas no formato de episódios, conforme propõem Graue e Walsh (2003), de forma a descrever e caracterizar pormenores das interações ocorridas.

Sendo assim, todo o trabalho foi construído buscando a aproximação dos sujeitos e suas impressões em torno do mundo, com o objetivo de "escavar o cotidiano", próprio da sociologia da vida quotidiana (PAIS, 2003). Esta pode ser entendida por uma lógica de descoberta que observa as rotinas e as rupturas, estando atenta à ação dos fatos quando, aparentemente, nada ocorre (PAIS, 2003a).

Para conseguir realizar os procedimentos de escavação do cotidiano, a investigação no campo foi subdivida em duas etapas. A primeira compreendeu uma fase exploratória, entre os meses de abril e junho de 2017. Na ocasião, procuramos traçar um mapeamento geral do campo, observando as rotinas das crianças em ambos os turnos, descrevendo os tempos-espaços da entrada, lanche, recreio e saída, bem como as formas de interação identificadas. Buscamos relatar, sobretudo, aqueles episódios que disponibilizavam roteiros aparentes de brincadeiras de lutinha e/ou brigas. Nessa fase, delimitamos as crianças que participariam da fase subsequente da pesquisa.

A segunda etapa foi realizada entre os meses de agosto e novembro de 2017, em que direcionamos as atenções para duas turmas de $4^{\circ}$ ano, no turno vespertino, reunindo 34 sujeitos de pesquisa, sendo 19 meninas e 15 meninos, com idades entre nove e 12 anos. Uma 
vez delimitado o grupo de participantes, concentramos observações nos tempos e espaços ocupados pelas crianças elencadas para a problematização do cotidiano. Dessa forma, as acompanhamos mais de perto, traçando recortes mais pormenorizados em suas interações e, desse modo, buscando vestígios para a discussão de nosso objeto.

A rotina de pesquisa durante a segunda etapa foi organizada para observação das aulas de Educação Física, do horário do lanche e do recreio, bem como da sala de aula. Alternarmos momentos de aproximação e distanciamento, a fim de tentar captar vários enquadramentos dos fenômenos analisados. A dificuldade em povoar os espaços dinâmicos de relacionamento entre crianças nos fez recorrer a procedimentos criativos, que tornassem a nossa "presença participante" menos invasiva e permitissem que todos ficassem mais à vontade. Esse processo contínuo e gradativo de aproximação foi permeado de constrangimentos e estranhamentos os quais, aos poucos, foram se convertendo em elementos primordiais para a compreensão do objeto.

A produção dos desenhos representou uma das técnicas indispensáveis para todo o processo. O tema requerido foi "As brincadeiras de 'lutinha' e as brigas na minha escola", realizado nos dias 7 e 9/11/2017. Ressaltamos que as produções ocorreram nas respectivas turmas selecionadas sem a presença das professoras. Nessas ocasiões, procuramos deixar as crianças à vontade para exposição do tema. Seguindo orientações de Gobbi (2002), após a produção dos desenhos, convidamos as crianças para conversar de forma individual, em ambientes fora de sala de aula. Dessa forma, permitimos maior desenvoltura das crianças na apresentação de seus desenhos, bem como uma menor timidez no trato de questões que poderiam expô-las a situações desconfortáveis em público.

A análise dos dados foi desenvolvida a partir do cruzamento das informações obtidas no campo em diálogo com a literatura proposta. A principais características das brincadeiras de lutinha e das brigas foram registradas no cotidiano da escola, sobretudo no tempo-espaço do recreio. Procuramos nos ensejos que tais manifestações foram pauta de diálogo com as crianças, atentar a elementos caracterizadores, identificados por meio de observação prévia delas em interação. Com isso, conseguimos pontuar aspectos que distinguem cada manifestação, buscando traços analíticos que contribuem para a compreensão do lugar dessas práticas corporais, com roteiros conflituosos, no cotidiano infantil.

Ademais, os desenhos e as falas das crianças a respeito das produções iconográficas colaboraram decisivamente na construção das categorias analíticas, uma vez que endossaram os paradoxos identificados. A seguir, apresentaremos as principais características das brincadeiras de lutinha e das brigas, num primeiro momento a partir dos excertos dos episódios observados, e, posteriormente e de forma mais aprofundada, por meio dos desenhos produzidos em campo.

\section{BRINCAR VERSUS BRIGAR! CARACTERÍSTICAS GERAIS}

Durante os momentos de observação nos diversos tempos-espaços da escola, registramos as mais variadas cenas de brincadeiras, brigas, bem como brincadeiras que se tornaram brigas e, ainda, brigas que acabaram ganhando contornos de uma simples brincadeira. Um aspecto a ser sublinhado é que essas distintas situações provocavam elementos em comum. Quando observadas pelas professoras ou funcionários da escola, as crianças eram prontamente alertadas com falas como: "Cuidado, vocês vão se machucar!", "Parem com isso!", "Isso não é brincadeira!", "Vou levá-los à direção!". Em outra perspectiva, por parte dos pequenos, a reação, 
na grande maioria das vezes, era acompanhada de respostas como: "É só brincadeira, tia", "É tudo de mentirinha... não é no sério não...". Nos casos em que as brigas eram de "verdade", as expressões faciais os entregavam, acompanhadas de xingamentos e/ou ameaças.

Das 34 crianças que participaram da pesquisa, 29 afirmaram em conversas já ter brincado de lutinha dentro ou fora da escola, sendo que desse universo 15 são meninas e 14 são meninos. Uma informação que merece destaque nessas brincadeiras é que boa parte das crianças citou o uso de gestos de derrubar/cair como ações primordiais na composição das lutinhas. Nesse contexto, o uso de socos, que são direcionados ao oponente e o atingem, já sugerem, a partir da fala deles, uma aproximação à conduta de briga. Os locais citados como os mais requisitados na escola para esse tipo de brincadeira são os parquinhos, pelo fato de disporem de espaços amplos, cobertos de areia e que ajudam no amortecimento das quedas.

No que se diz respeito às brigas, 21 crianças testemunharam já ter participado de algum episódio dessa natureza, sendo 11 meninas e dez meninos. Identificamos, ainda, que o corpo das crianças acusa pistas importantes para identificar o início de uma briga. Por exemplo, nos episódios em que acompanhamos, todos os participantes, indistintamente, apresentaram expressões faciais de raiva, bem como gestos ríspidos, sem aparentar qualquer tipo de cuidado ou pudor com o outro. O local predileto da escola para a realização das brigas, segundo eles, é a parte de trás da escola, em uma porção escondida pelas paredes do ginásio.

Ainda com relação às brigas na escola, pudemos perceber características que dão contornos à manifestação protagonizada pelas crianças. Em alguns dos casos relatados, a briga começou como uma simples brincadeira e, em decorrência da transgressão de uma norma implícita ou o excesso de alguém - como um empurrão desproporcional, por exemplo -, acabou desembocando em atos de agressão desmedida de ambas as partes. Outro aspecto a ser destacado é que, claramente, o objetivo primordial da briga é subjugar o oponente, seja machucando, causando-lhe dor ou humilhando-o em frente aos pares. Nesse sentido, o outro é considerado como "alvo" e não um mero adversário.

Ademais, com base nas características registradas, pudemos inferir as principais motivações das brigas protagonizadas pelas crianças, das quais destacamos quatro, sendo elas:

a) oriundas de uma provocação, como xingamento, apelido, pegar em alguma parte do corpo;

b) iniciadas de um fato ocasional, como um esbarrão, uma pisada no pé; ou de um revide;

c) de resultado da disputa por um espaço ou objeto;

d) mudança dos rumos de um jogo ou brincadeira; ou ainda de uma briga de "mentirinha". Contudo, assim como a brincadeira de lutinha, as brigas só acontecem quando há uma mútua motivação das partes envolvidas.

Ressalvamos que, entre os participantes da pesquisa, apenas quatro crianças, todas meninas, relataram não ter se envolvido em brincadeiras de lutinha ou em brigas. Destacamos, finalmente, a conversa com uma das crianças que compôs nossa pesquisa. Larissa Manoela ${ }^{1}$ (dez anos), em sala de aula, próximo ao horário do recreio em um dos dias de observação, abordou sua relação conflituosa com os colegas de classe, fazendo o seguinte comentário: "Tio, não faço questão de me dar bem com eles... eu gosto é de treta!". Questionamos: "Como assim, treta? Me explica melhor?". Com semblante sarcástico, ela respondeu: "Eu gosto de confusão,

1 Como forma de preservação de suas identidades, solicitamos, ao longo da pesquisa de campo que cada uma das crianças escolhesse um nome fictício. 
de brincar de sacanear mesmo... Meus vizinhos são tudo barraqueiro. Eles caçam confusão e eu vou pro portão ver. Tem de tudo, tio... eu adoro ver os barracos, mas gosto mesmo é de brigar [...]" (DIÁRIO DE CAMPO, 06/11/2017). Percebemos que o imaginário em torno das "tretas" e das dissonâncias que emergem das relações sociais na comunidade e na escola se converte em roteiros de condutas desempenhadas pelas crianças, sejam em brigas, como até mesmo nas próprias brincadeiras. A fala de Larissa Manoela, portanto, confirma a categoria "conflito" no cotidiano infantil.

\section{BRINCAR E O BRIGAR NAS “ZONAS DE RUPTURA” DO COTIDIANO}

Por meio dos desenhos, as crianças lançaram mão de variadas leituras das brincadeiras de lutinha e das brigas na escola. Curiosamente, ao analisar as produções, concluímos que foram endossadas características que ratificavam os paradoxos, sugerindo mais zonas de ruptura que, necessariamente, de continuidade. Optamos por considerar as distinções apontadas, num primeiro momento, pelos sujeitos e as reconhecemos como categorias no processo de problematização das próprias narrativas, sendo elas:

a) "Bem versus mal",

b) "Mocinho versus bandido",

c) "Alegria versus tristeza",

d) "Mentira versus verdade",

e) "Real versus virtual",

f) "Vencedor versus perdedor" e, por fim,

g) O brincar e o brigar sob o mesmo patamar, tendo a violência explícita como principal roteiro.

Vale pontuar que, por mais que tais categorias sobrelevem os eixos condutores em queas crianças se pautaram na diferenciação das práticas, são sugeridos rastros para o delineamento das zonas de coalisão, uma vez que estas, subliminarmente, trazem interpretações sobre 0 "corpo-cotidiano" dos pequenos e sobre o conflito como um regulador das próprias práticas corporais infantis. Ressaltamos que, dos 34 desenhos, elencamos sete que ilustravam com maior riqueza de detalhes as características suscitadas. Assim, apresentamos a seguir as categorias elaboradas, partindo do ponto de vista dos sujeitos da pesquisa.

\section{a) Bem versus mal}

Quando questionada sobre o que pensava a respeito das brincadeiras de lutinha e as brigas na escola, Estefany (nove anos), respondeu: "Eu acho que brincar é bater bem fraquinho e brigar de verdade é bater forte, pra machucar [...]". Sobre o seu desenho, relatou: "[...] 0 anjinho é a luz, é o bem... e o capetinha o mal. Na briga tem o mal, o bem tem na brincadeira". Perguntamos o motivo pelo qual ela usou esses exemplos e, após pensar um pouco, respondeu: "Deus é o bem e não quer ver a gente sofrer, a briga tem maldade, as pessoas se matam [...]" (DIÁRIO DE CAMPO, 07/11/2017).

Conforme Corsaro (1992), as brincadeiras podem expor roteiros imaginários que permitem a criação de universos lúdicos em um processo dinâmico em que compartilham entre si emoções diversas, bem como representações sociais da bondade, da maldade, dentre outras. Fica clara, assim, a associação das práticas no ambiente escolar com sentidos e significados para além delas. 
Figura 1. Desenho de Estefany (nove anos)

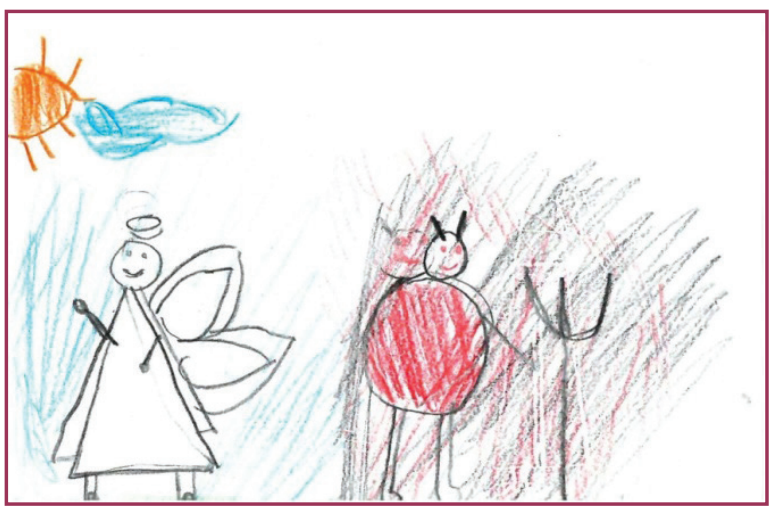

Fonte: Registros da pesquisa.

Percebemos que o imaginário em torno do bem e do mal retratado no desenho de Estefany representa símbolos que pairam no imaginário infantil, inspirados de forma significativa por pressupostos religiosos. $\mathrm{O}$ anjo sorridente e bondoso está presente na brincadeira, pois proporciona bem-estar e alegria aos participantes. Por sua vez, a figura demoníaca representa a maldade, a dor e a tristeza. Estefany, inclusive, teve o cuidado de enfatizar características marcantes de ambos, como a luz, o sol, a auréola e as asas do anjo, bem como a escuridão, os chifres, o tridente e os tons avermelhados alusivos ao fogo.

b) Herói versus bandido

Sobre seu desenho, Messi (12 anos) relatou: "Aqui é uma guerra do herói contra os bandido. Um cara com máscara de palhaço, com arma e com faca. Pode ser tudo de brincadeira, mas acontece no sério". Questionamos sobre o uso da máscara do palhaço pelo bandido, e o garoto respondeu: "[...] Usa lá nos Estados Unidos. A máscara macabra é pra ninguém descobrir a cara do outro, senão, se ver na rua, pega... Bandido se esconde!". Sobre o herói, o garoto concluiu: "O cara do bem sou eu, salvando o povo da bandidagem". Perguntamos: "Tipo policial?". Com prontidão, repreendeu: "Cana não! Tipo os caras dos filme cheio de arma...". Questionamos se tinha retratado uma brincadeira ou uma briga, e o garoto concluiu: "Pode ser qualquer um, depende de quem tiver lá" (DIÁRIO DE CAMPO, 07/11/2017).

Figura 2. Desenho de Messi (12 anos)

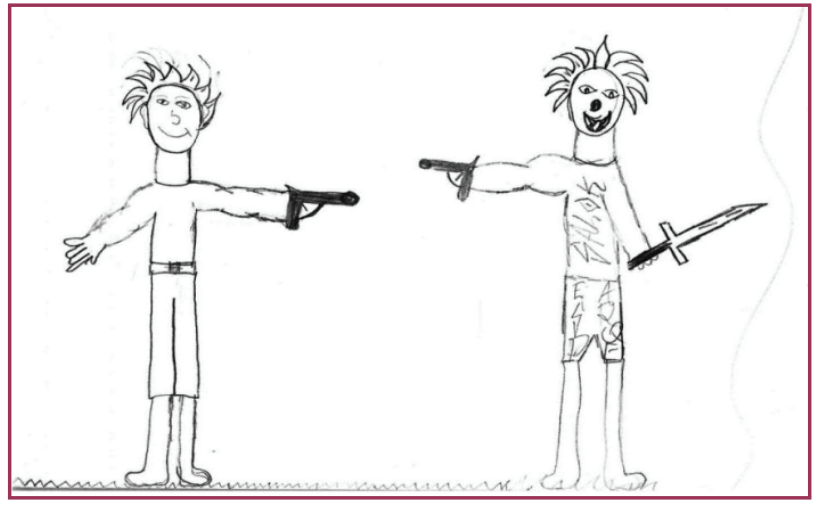

Fonte: Registros da pesquisa.

Messi expôs sua compreensão baseada no imaginário do herói contra 0 bandido, indo ao encontro da perspectiva de bem e do mal retratada anteriormente. Nesse contexto, 
pudemos perceber a incidência direta do conteúdo midiático na cultura lúdica (BROUGÈRE, 1998). Um ponto a ser destacado é a associação da imagem do herói "justiceiro" dos filmes de ação, desarticulada da figura do policial. A imagem do bandido "escondido" pelas máscaras também foi algo que nos causou curiosidade, dispondo de impressões das crianças acerca do "fora da lei".

Ao final, o garoto tocou em um ponto que consideramos relevante na análise das brincadeiras e brigas: a diferença entre práticas depende de "quem tá lá", ou seja, dos protagonistas das ações. Em outras palavras, o que define o significado das práticas não é o observador, mas as intencionalidades dos sujeitos envolvidos, que, segundo Goffman (1999), são orientadas pelo meio social e em processo de interação. Inclusive, os sentidos apresentados por Messi representam uma síntese de vivências na sua escola, na comunidade em que mora, bem como dos filmes "cheios de arma" a que teve acesso.

\section{c) Alegria versus tristeza}

Sob outra perspectiva, Mohana (nove anos) fez o seguinte comentário sobre seu desenho: "Aqui eles sorriem, aqui eles xingam... os golpes que eles dão um no outro sai sangue que não é de brincadeira, não". Enfática em sua compreensão sobre brincadeira, pontua: "Brincar é tipo a gente se divertindo, nesse caso pra mim brincar se machucando não é brincadeira... eu não me divirto me machucando, fico triste. Fico feliz brincando livre". Alerta, ainda, sobre alguns aspectos problemáticos, em seu ponto de vista, das brigas: "[...] brigar é uma coisa meio perigosa, vi vários casos na televisão de bandidos baterem na mulher ou de bater em alguém até o outro morrer, vai que morre aqui também....". De forma resumida, expôs 0 que considera como as principais diferenças entre as manifestações: "Na briga tem xingamento, tristeza, na brincadeira, não. Não gosto de brincadeira de bater nem de mentirinha... gosto de ser alegre" (DIÁRIO DE CAMPO, 09/11/2017).

Figura 3-Desenho de Mohana (nove anos)

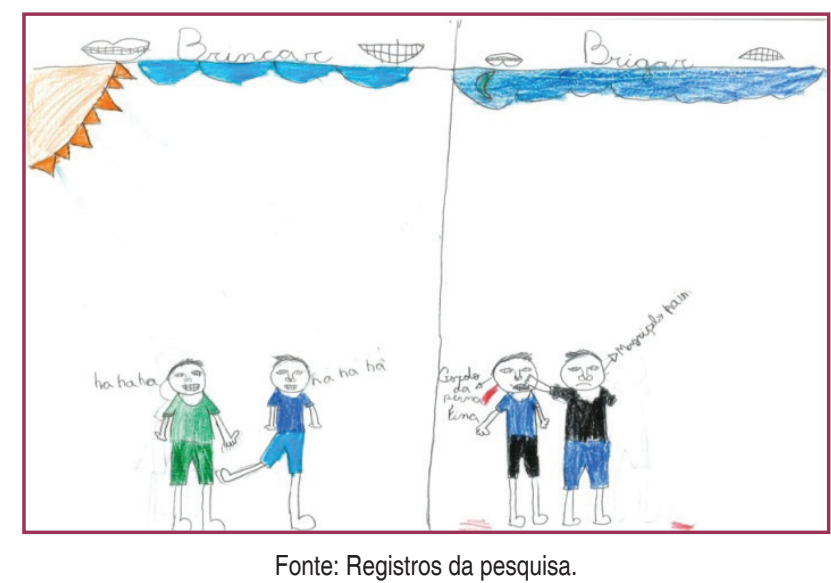

O estado de alegria é posto pela garota como principal parâmetro na distinção entre o brincar e o brigar. No desenho, utilizou os sorrisos e o cenário ensolarado como forma de representação das brincadeiras. Por outro lado, para ilustrar as brigas, colocou um pano de fundo com aparente temporal, cheio de nuvens, bem como sujeitos demonstrando expressões faciais de raiva e disparando insultos uns aos outros. Um aspecto curioso que reparamos, no que diz respeito aos gestos de combate, foi que na brincadeira os golpes são desferidos nos 
membros inferiores e sem contato direto, já na briga o rosto é acertado como alvo, fazendo um dos personagens sangrar.

Mais uma vez as mídias são citadas como um ponto de referência nas compreensões das crianças. No caso de Mohana, a televisão foi referendada por meio de um episódio em que bandidos bateram em uma mulher até levá-la à morte. A garota associou esse ato de violência banal e fatal como algo a ser ponderado na análise das brincadeiras e das brigas na própria escola, pois, segundo ela, mesmo brincando, gestos de "lutinha" podem ser perigosos.

Nesse bojo, os eixos interacionais entre crianças são interceptados por eixos socializadores institucionais, em que ocorrem a reprodução de alguns estereótipos dominantes do mundo adulto (SARAMAGO, 1994). Esses estereótipos atuam, inclusive, na interpretação das práticas corporais, em que são construídos núcleos de afinidades identitárias a partir do imaginário em torno das mídias e da violência, que contribuem decisivamente na compreensão das brincadeiras de lutinha e das brigas (FARIAS; WIGGERS, 2015).

d) Mentira versus verdade

Para Maiara (dez anos), "[...] brincar, brigar, é tudo tipo mentirinha e de verdade, sabe?". Assinalamos com a cabeça que não havíamos entendido e pedimos que nos explicasse, então acrescentou: "É tipo assim, eu finjo que tô brigando às vezes quando na hora é brincadeirinha, é tipo uma novela, [...] porque só pode tapa e murro. Começamos a discutir, mas tudo de brincadeira". Comentamos: "Isso na brincadeira, né? E na briga?". Com uma pausa e esboçando uma expressão de dúvida, disse: "Pode ser nos dois, tem coisa que é de mentira e tem coisa que é de verdade" (DIÁRIO DE CAMPO, 07/11/2017).

Figura 4. Desenho de Maiara (dez anos)

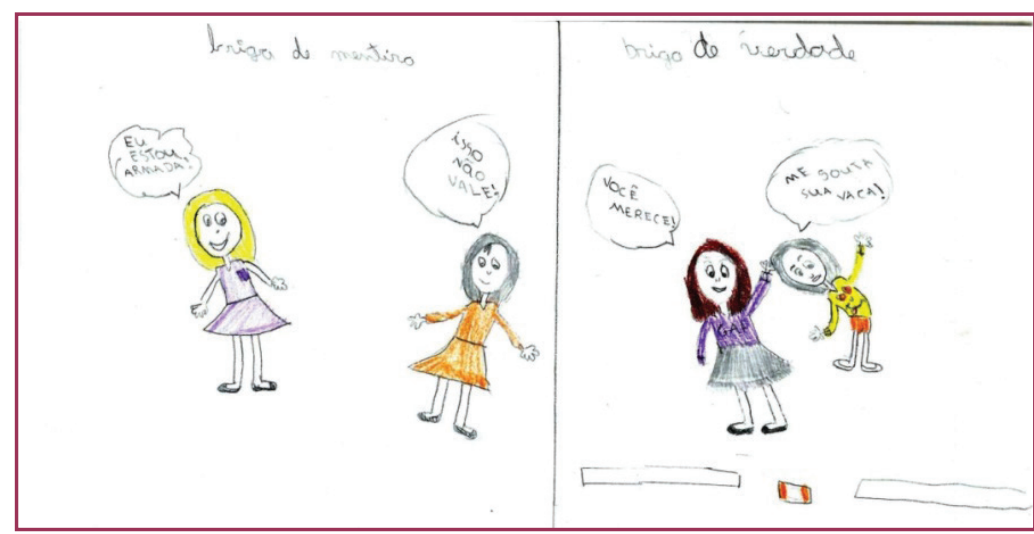

Fonte: Registros da pesquisa.

As nuances entre o que é de mentira e o que é de verdade no que tange às práticas corporais infantis não são captáveis com facilidade, sobretudo quando as manifestações analisadas são dúbias e podem assumir caracteres da outra sem perder seus principais objetivos. Maiara expôs algo que entendemos ser o alicerce de suas compreensões, que é, novamente, a intencionalidade do sujeito frente ao episódio que protagoniza.

Ademais, Brougère (2010) aponta que as crianças se situam na brincadeira por meio de códigos que emanam de conteúdos midiáticos, como das telenovelas citadas por Maiara, por exemplo. A partir da ressignificação desses códigos é que as narrativas ganham forma $\mathrm{e}$ 
elas vão montando as peças do quebra-cabeça do cotidiano, entre o que é de verdade e o que é de "mentirinha". Ilustra, assim, a importância do roteiro da narrativa para a interpretação do fenômeno, que, independentemente de sua natureza, traz consigo delineamentos do conflito como parte constituinte das próprias interações entre crianças.

e) Real versus fantasia

Ao abordar seu desenho, Fábio (nove anos) relatou: "Nesse aqui [na direita] eles tão brincando... O outro [esquerda] são dois ninjas brigando, pra ficar no comando da cidade... um é do mal e outro é do bem, vi em um desenho...". Pedimos que nos falasse mais sobre a produção, assim, continuou: "Nesse aqui tem quatro meninos brincando de lutinha na rua. É que esse aqui é um ninja da água, esse da terra, esse do fogo e esse do vento... Eles se encontraram e começaram a duelar pra ver quem ia ficar no comando". Esclarecendo a diferença entre as cenas retratadas: "Um é real e o outro é tipo da imaginação. Na briga de verdade um quer dominar a cidade, na de mentirinha eles acharam uma caverna e começaram a brigar de brincadeira..." (DIÁRIO DE CAMPO, 07/11/2017).

Figura 5 - Desenho de Fábio (nove anos)

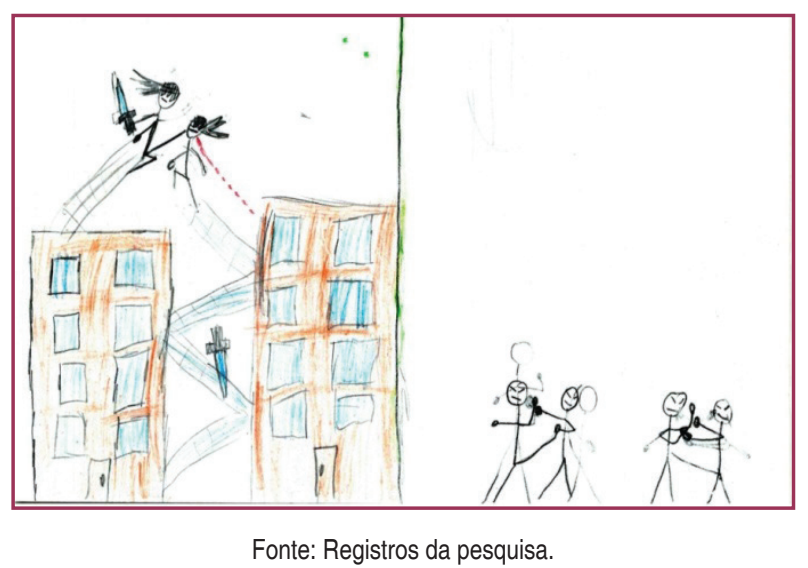

Segundo Pais (1993, p.108), "A posse do real é uma verdadeira impossibilidade [...]", no entanto, sugere a imaginação como caminho para compreender o próprio cotidiano, nesse caso em específico, o infantil. Outrossim, Sirota (2012) acrescenta que as crianças interpretam e reproduzem de forma criativa o cotidiano por meio de uma dinâmica de representações de papéis que transitam entre o real e a fantasia.

Fábio apresentou, em ambos os desenhos, um forte apelo de roteiros de desenhos animados. 0 garoto não distinguiu 0 que era real e 0 que era produto do imaginário, pois nas duas partes os combates dispunham de narrativas orientadas pela fantasia. Concluímos, desse modo, que as histórias de guerreiros, ninjas e lutadores atuam de forma significativa na interpretação, não só das brincadeiras e brigas, mas do próprio gesto de luta e dos símbolos que são atravessados pelo corpo em combate.

f) Vencedor versus perdedor

Bob Esponja (dez anos) entende que tanto as brincadeiras de lutinha quanto as brigas são formas de competição, em que um quer ser melhor que o outro. Segundo a garota: "Brigar é uma coisa de machucar, já brincar é uma coisa pra se divertir, só que os dois um é melhor que 
o outro. Meninos gostam de saber quem é mais forte... Idiotas!". Sobre o desenho, comentou sorridente: "Aqui o menino matou o colega de brincadeira e ficou com o troféu...". Realizando o mesmo gesto com os braços, que foi retratado no desenho, finalizou: "Não sou esperta? Minha imaginação é ótima" (DIÁRIO DE CAMPO, 07/11/2017).

Figura 6 - Desenho de Bob esponja (dez anos)

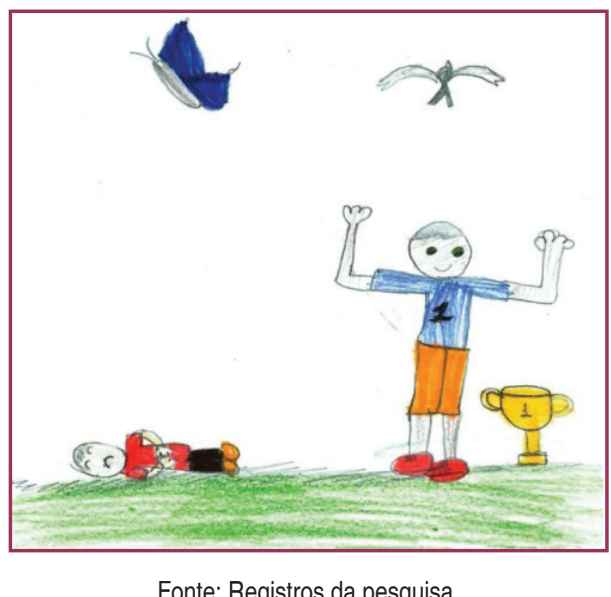

A cena retratada por Bob Esponja suscita um debate em torno dos desafios de virilidade entre os meninos. Durante a observação, não foi incomum a presença de garotos se desafiando em uma aparente busca por reconhecimento entre seus pares. 0 mais forte, o mais rápido, 0 bom de briga adquire respeito entre os colegas e sempre é requisitado para as brincadeiras e para as rodinhas de conversa.

Como constructos simbólicos de masculinidades, as lutinhas entre meninos lançam mão de elementos "generificados", subsumidos em expressões como "briga é coisa de macho", "se não bater, é porque é mulherzinha". Tais leituras contribuem para compreensões estereotipadas de gênero, em que o campeão das "lutinhas" é aquele que bate no colega e por vezes o machuca (CRUZ; CARVALHO, 2006). Por mais que não tenha havido distinção entre o brincar e o brigar no desenho, foi retratado o finalístico de ambos, no que tange à construção das figuras do "vencedor" e do "perdedor" nas culturas infantis.

g) Brincando e brigando: roteiro de violência explícita

Sobre o desenho, Muralha (dez anos) comentou: "[...] esse aqui brincando [esquerda], esse aqui [direita] brigando de verdade. 0 cara dá um soco no olho do cara que voou, depois deu um chute nos negócios com a chuteira de trava [...]". Acrescentou: "A briga pra mim é isso... brigar até morrer. Aqui esse cara tá matando o outro... ele é presidiário [...]. Ele fugiu da cadeia e matou o cara por acerto de conta... arrancou o célebro". Comentamos: "Nossa! Bem sangrento. Onde você viu isso?". Quase nos interrompendo, ele explicou: "Não que eu vi. Eu não vi assim cara a cara, mas acontece direto". Comentou, ainda, a violência explícita da brincadeira representada no desenho: "Aqui é uma violência diferente, saca? É brincadeira de omelete". Questionamos: "O que é omelete?". Transparecendo timidez, explicou: "Porque o cara tá dando chute nas coisas do outro cara... ele fez um omelete" (DIÁRIO DE CAMPO, 09/11/2017). 
Figura 7- Desenho de Muralha (dez anos)

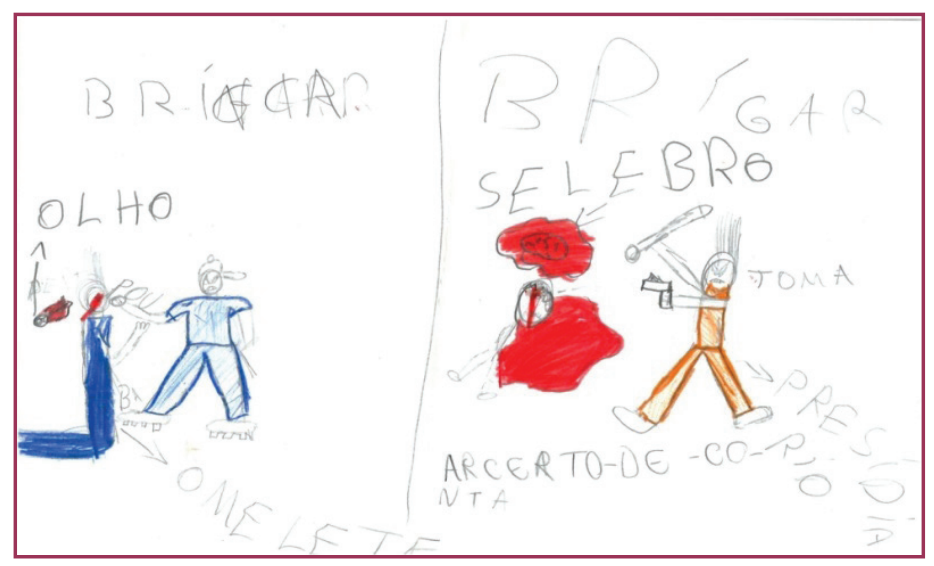

Fonte: Registros da pesquisa.

As práticas corporais infantis que trazem consigo roteiros de agressividade ou gestos alusivos a violência expõem embates simbólicos que extrapolam esses próprios gestos e sintetizam uma rede de significações compostas pelas culturas infantis, pela cultura escolar, bem como cultura do entorno. No bojo desses encontros, há um jogo de tensões sociais que atua diretamente no corpo das crianças, sublinhando regras de cerceamento e gerando válvulas de transgressão das normas instituídas (BARBOSA et al., 2017; RODRIGUES, 2012).

Tanto no desenho como na fala, Muralha relatou com tranquilidade roteiros de violência explícita. Sem perceber, o garoto colocou a brincadeira e a briga em patamares parecidos, levando em consideração que os gestos de agressividade nutrem o imaginário em torno das manifestações. Percebemos que, num primeiro momento, o garoto retratou essa confusão, inclusive, na escrita da própria legenda da primeira cena.

Observamos, a partir da conversa com Muralha, que a violência externa à escola atua significativamente em algumas interpretações das crianças. Isso, a nosso ver, não corresponde a um indicativo de que elas estão mais ou menos violentas, mas acusa um alerta para as informações que andam tendo acesso e que interferem em suas leituras de mundo.

\section{CONSIDERAÇÕES FINAIS}

Nos registros de campo, foi possível observar alguns temas que apresentam "frestas" entre as narrativas adultas e infantis que, de certo modo, ilustram os conflitos nas experiências do "ser" criança e forjam as suas compreensões de corpo. Dentre tais temas, destacamos questões acerca da busca pela excitação do proibido, relacionadas aos imaginários em torno das mídias, de questões de gênero, da violência e da morte. Embora os temas referendados não tragam diretamente interpretações relacionadas às brincadeiras de lutinha e das brigas, expõem tabus do cotidiano dos sujeitos que ocupam a escola.

Para além disso, o conflito foi constatado como um importante mediador das experiências infantis, considerando que a escola também é um espaço de disputas por poder e visibilidade. Desse modo, pudemos perceber um jogo tenso entre culturas, sobretudo entre as culturas infantis e a cultura escolar, que demonstram resistências de ambas as partes, podendo ser compreendidas por meio da noção de conflito, anteriormente abordada. Portanto, para avançarmos na compreensão dos conflitos emergentes da experiência infantil, precisamos enfrentar essas discussões "escondidas" na escola. 
As maneiras pelas quais as crianças fabricam suas impressões de corpo e que constituem as rotas do cotidiano dentro e fora da escola permitem reinvenções nos modos de viver a infância, dando contornos ao que chamamos de "corpo-cotidiano". As brincadeiras de lutinha e as brigas, como manifestações das culturas infantis, ilustram bem as tensões que constituem esse corpo-cotidiano, especialmente por se fundarem em paradoxos entre narrativas adultas e infantis.

Por fim, ressaltamos que as produções analisadas na pesquisa endossaram características ambíguas entre o brincar e o brigar e expuseram roteiros de confronto entre as noções de "bem e mal", "herói e bandido", "alegria e tristeza", "mentira e verdade", "real e virtual" e "vencedor e perdedor". Outrossim, os registros de campo permitiram a identificação de categorias que evidenciam as brincadeiras de lutinha e as brigas sob dimensões paradoxais do cotidiano infantil, que carregam no seu bojo aspectos circundantes ao conflito enquanto mediador das relações concebidas dentro e fora da escola.

\section{REFERÊNCIAS}

BARBOSA, Raquel Firmino Magalhães et al. Brincadeiras lúdico-agressivas: tensões e possibilidades no cotidiano na educação infantil. Movimento, v. 23, n. 1, p. 159-170, jan./mar. de 2017.

BROUGÈRE, Gilles. Brinquedo e cultura. São Paulo: Cortez, 2010.

BROUGĖRE, Gilles. A criança e a cultura lúdica. In: KISHIMOTO, Tizuko M. (org.). 0 brincar e suas teorias. São Paulo: Cengage Learning, 1998. p. 19-32.

CANDREVA, Thábata et al. A agressividade na educação infantil: o jogo como forma de intervenção. Pensar a Prática, v. 12, n. 1, p. 1-11, abr. 2009.

CHÂTEAU, Jean. 0 jogo e a criança. São Paulo: Summus, 1987.

CORSARO, William. Entrada no campo, aceitação e natureza da participação nos estudos etnográficos com crianças pequenas. Educação e Sociedade, v. 26, n. 91, p. 443-464, maio/ ago. 2005.

CORSARO, William. Interpretative reproduction in children's peer cultures. Social Psychology Quarterly, v. 55, n. 2, p.160-177, 1992.

CRUZ, Tânia Mara; CARVALHO, Marília Pinto de. Jogos de gênero: o recreio numa escola de ensino fundamental. Cadernos Pagu, v. 26, p. 113-143, jan./jun. 2006.

DADOUN, Roger. A violência: ensaio acerca do "homo violens". Rio de Janeiro: DIFEL, 1998.

ELIAS, Norbert. Introdução à sociologia. Lisboa: Edições 70, 2005.

FARIAS, Mayrhon José Abrantes. "Não é briga não... é só brincadeira de lutinha": cotidiano e práticas corporais infantis. 2015. 130f. Dissertação (Mestrado em Educação Física) - Faculdade de Educação Física, Universidade de Brasília, Brasília, 2015. 
FARIAS, Mayrhon José Abrantes; WIGGERS, Ingrid Dittrich. Cotidiano e práticas corporais infantis: o lúdico e a violência em cena. Motrivivência, v.27, n.45, p.58-73, set. 2015.

GOBBI, Márcia. Desenho infantil e oralidade: instrumentos para pesquisas com crianças pequenas. In: FARIA, Ana Lúcia Goulart; DEMARTINI, Zeila de Brito Farbi; PRADO, Patrícias Dias. Por uma cultura da infância: metodologias de pesquisa com crianças. Campinas: Autores Associados, 2002. p. 69-92.

GOFFMAN, Erving. A representação do eu na vida cotidiana. 8. ed. Petrópolis: Vozes, 1999.

GRAUE, M. Elizabeth; WALSH, Daniel. J. Investigação etnográfica com crianças: teorias, métodos e ética. Lisboa: Triunfadora-artes gráficas, 2003.

HUIZINGA, Johan. Homo ludens: o jogo como elemento da cultura. São Paulo: Perspectiva, 2010.

PAIS, José Machado. Culturas juvenis. Lisboa: Imprensa Nacional, 2003.

PAIS, José Machado. Nas rotas do quotidiano. Revista Crítica de Ciências Sociais, n. 37, p.105 - 115, jun. 1993.

PAIS, José Machado. Vida cotidiana: enigmas e revelações. São Paulo: Cortez, 2003a.

RODRIGUES, Josiane. Brincadeiras violentas: um estudo etnográfico das linguagens corporais agressivas. 2012, 118f. Dissertação (Mestrado em Educação) - Faculdade de Educação, Universidade Federal de Mato Grosso, Mato Grosso, 2012.

SARAMAGO, Silvia Sara Sousa. As identidades da infância: núcleos e processos de construção das identidades infantis, Problemas e Práticas, v.16, p. 151-171, 1994.

SIMMEL, Georg. Sociologia. São Paulo: Ática, 1983.

SIROTA, Régine. A socialização no cotidiano: os trunfos de uma etnografia do minúsculo. In: BROUGĖRE, Gilles; ULMANN, Anne-lise (org.). Aprender pela vida cotidiana. Campinas, Autores Associados, 2012. p. 279-292.

WEBER, Max. Economia e sociedade. Brasília: Universidade de Brasília, 1999. 